\title{
Causes and Breaking of Seed Dormancy in Flowering Dogwood (Cornus florida L.)
}

\author{
Hailin Liu, Cunmeng Qian, Jian Zhou, Xiaoyan Zhang, Qiuyue Ma, \\ and Shuxian $\mathbf{L i}^{1}$ \\ The Southern Modern Forestry Collaborative Innovation Center, Nanjing \\ Forestry University, 210037 Nanjing, China
}

Additional index words. Cornus florida, dormancy, germination, water uptake, endogenous inhibitors, break dormancy

\begin{abstract}
Cornus florida seeds show strong dormancy. In this study, we investigated the causes of the dormancy by assessing the permeability of the stony endocarp, the germination of seeds after mechanical dissection, and the effect of endogenous inhibitors. Water uptake by intact and cracked seeds during imbibition showed that the endocarp formed a strong barrier for water absorption. Meanwhile, extracts from endocarp decreased the germination frequency of chinese cabbage seeds from $99.3 \%$ (control) to $\mathbf{2 . 7 \%}$. Therefore, the endocarp was the mechanical barrier and contained endogenous inhibitors for seed germination. However, the germination percentage of decoated seeds and dissected seeds with the exposed radicle were only $13.3 \%$ and $28.7 \%$, respectively. It was found that the endosperm also played a role in seed dormancy. Extracts from endosperm decreased the germination frequency of chinese cabbage seeds from $99.3 \%$ (control) to $53.0 \%$. By contrast, extracts from embryo did not affect the germination of chinese cabbage seeds. When tested with the excised embryos, germination percentage was up to $85.3 \%$ at the 16th day of incubation. Taking these results together, we concluded that the endocarp and endosperm were responsible for seed dormancy in $C$. florida. To break the seed dormancy of $C$. florida, stratification and soaking in sulfuric acid are the effective means. The highest germination frequency was achieved by immersing seeds in $\mathbf{9 8 \%}$ sulfuric acid for 10 minutes, then soaking the seeds in $500 \mathrm{mg} \cdot \mathrm{L}^{-1}$ gibberellic acid $\left(\mathrm{GA}_{3}\right)$ for 72 hours before cold stratification at $5^{\circ} \mathrm{C}$ for 60 days.
\end{abstract}

Flowering dogwood (C. florida L.), a member of the subgenus Benthamidia in Cornus, is a small- to medium-sized deciduous tree native to eastern North America (Borer et al., 2013; McLemore, 1990; Rushforth, 1999). The species is prized for the ornamental value of the pink, red, or white petal like, enlarged bracts in early spring, and brilliant red foliage and bright red berries in autumn. As noted by the U.S. Department of Agriculture Census of Horticultural Specialties (USDA-NASS, 2010) from retail and wholesale sales, in the United States, and especially in states such as Tennessee, C. florida is an economically important ornamental tree and may also be used as an important food source for wildlife in forests when its fruits ripen in autumn (Paul and David, 2008; Stiles, 1980). In addition, $C$. florida is widely considered as a calcium pump, increasing the rates of mineralization of the forest litter and soil because of the high calcium concentrations in

Received for publication 12 Jan. 2015. Accepted for publication 24 Apr. 2015.

Funding for this work was provided by the Natural Science Foundation of China (31270711) and the Priority Academic Program Development (PAPD) Program at Nanjing Forestry University. This study was also supported by the Innovative Research Teams Program in Universities of Jiangsu Province, and Innovative Research Teams Program of the Educational Department of China.

${ }^{1}$ To whom reprint requests should be addressed; e-mailshuxianli@njfu.com.cn. its foliage (Holzmueller et al., 2007; Thomas, 1969).

Typically, C. florida is propagated from seeds, but the seeds usually develop strong dormancy (Coartney et al., 1989), which may be a great challenge for seed reproduction (Dirr and Heuser, 1987). Studied with $C$. kousa var. Chinensis, Fu et al. (2013) indicated that the dormancy of chinese dogwood could be classified as physiological dormancy due to the existence of inhibitory substances in the endosperm. However, the causes of $C$. florida seed dormancy remains largely unknown thus far, except that Laufmann and Wiesner (1998) reported rapid germination of eastern dogwood ( $C$. florida cv. Small) by embryo extraction, cut cotyledons, and $\mathrm{GA}_{3}$. Normal seed germination of $C$. florida requires a moist prechill treatment at $3-5^{\circ} \mathrm{C}$ for 3-4 months. In this study, we aimed to identify the multifaceted causes and to establish a practical and powerful method to successfully break the seed dormancy of $C$. florida that can be applied in seed reproduction practice.

\section{Materials and Methods}

Source of seeds. The seed of C. florida is encased within a stony endocarpic pit (hereafter seeds with endocarp are referred to as the seed). In this study, the seeds of $C$. florida were imported via Lovelace Seed Company (Elsberry, MO) in Spring 2013 and stored at $4{ }^{\circ} \mathrm{C}$. The seeds were collected from Knoxville, TN.
Water permeability of the endocarp. To test whether the hard stony endocarp may restrict water imbibition for germination, two experiments were performed to test the water absorption capability of the seed. In Expt. I, 30 intact seeds enclosed within the endocarp were weighed on an electronic balance accurate to $0.001 \mathrm{~g}$, then were immersed in $200 \mathrm{~mL}$ distilled water at room temperature for $168 \mathrm{~h}$. At 12-hour intervals, the seeds were removed from the water, surface dried using filter paper, and weighed. The seeds were then reimmersed. The final weight measurement was recorded after soaking for 14 cycles for 168 h. In Expt. II, the same procedure was repeated except for the fact that the endocarp was cracked in the micropylar region of pliers, otherwise, the procedures were identical to those used in Expt. I. The two experiments were conducted using three replicates of 30 seeds each. In each experiment, the water uptake ratio was calculated and expressed as a percentage of the seed fresh weight.

Germination after mechanical manipulation. Three experiments were performed to identify whether different tissues restrict the germination of $C$. florida seeds. Before the experiments, seeds were treated as follows: a) the stony endocarp was completely removed following breakage using a pair of pliers ("decoated seeds") (Fig. 1A); b) the decoated seeds were carefully dissected using a singleside blade to expose the radicle ("radicleexposed seeds") (Fig. 1B); and c) the embryo was excised from the seed (Fig. 1C). After these preliminary treatments, the materials were incubated on moist absorbent cotton at $25{ }^{\circ} \mathrm{C}$ and an 8-h photoperiod. During incubation, the seeds were watered every $2 \mathrm{~d}$. Germination was monitored every second $\mathrm{d}$ for $16 \mathrm{~d}$. The germination percentage was determined in accordance with the International Seed Testing Association (ISTA) (2011) guidelines. Three replicates of 50 seeds were used in each of the three experiments.

Extraction of inhibitors of seeds. Inhibitors of $C$. florida seed germination were extracted from the endocarpic pit, the endosperm, and the embryo using methanol as the extract solvent. The extraction procedure was conducted as that described by $\mathrm{Hou}$ et al. (2014). First, the endocarps, the endosperms, and the embryos were excised separately. Then, the endocarps were ground into powder in a mill grinder, and the endosperms and the embryos were separately ground into powder in liquid nitrogen. The powdered samples were extracted with methanol in a soxhlet apparatus. The extracts were obtained by the following procedures: the powdered samples $(2.5 \mathrm{~g})$ were suspended separately in $40 \mathrm{~mL}$ of $80 \%(\mathrm{v} / \mathrm{v})$ methanol at $5{ }^{\circ} \mathrm{C}$ for $24 \mathrm{~h}$ three times. Subsequently, the combined supernatants from the extractions for each tissue were evaporated under vacuum at $37^{\circ} \mathrm{C}$ to remove the solvent completely. Finally, $2 \mathrm{~mL}$ of each extract was diluted to $100 \mathrm{~mL}$ with distilled water.

The activity of inhibitors in the extracts was determined by incubating nondormant chinese cabbage seeds in petri dishes moistened with the extracts. Three replicates of 

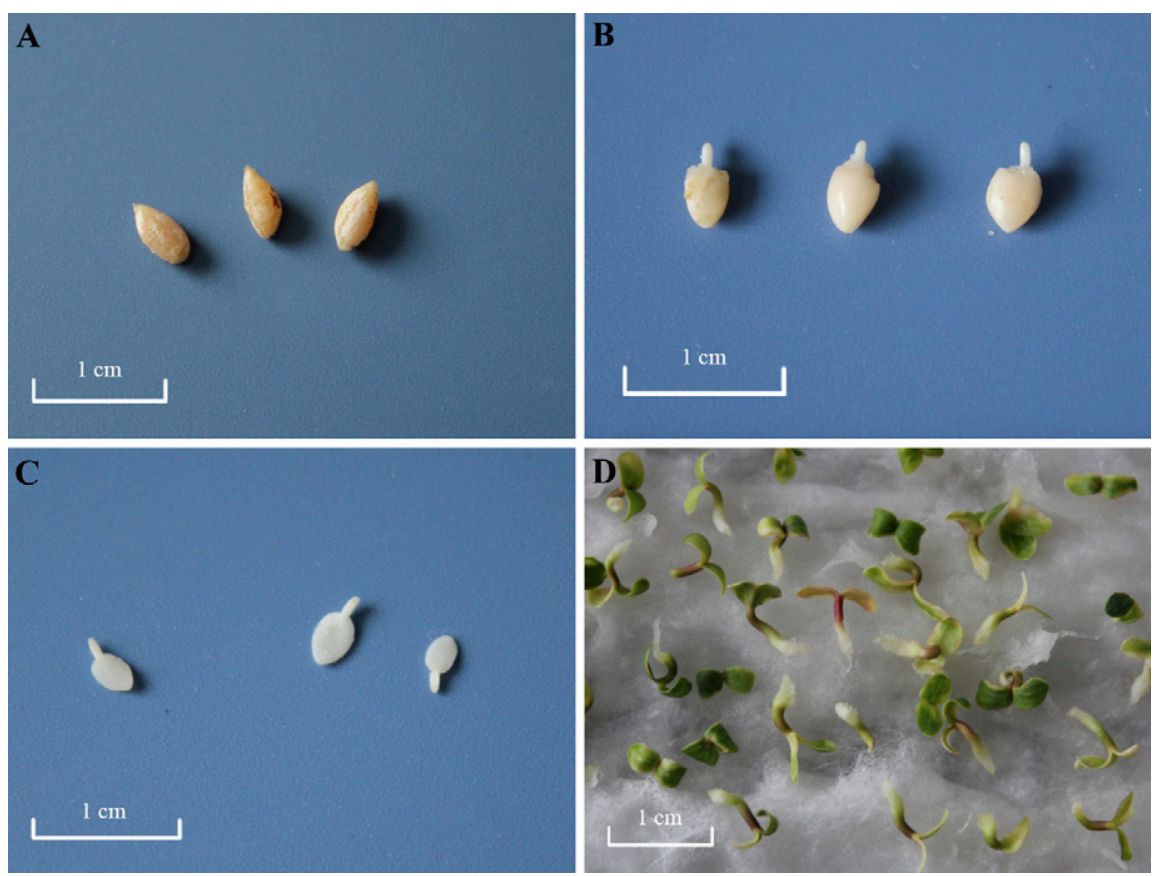

Fig. 1. Germination of $C$. florida seeds after mechanical dissection. (A) The decoated seeds with intact endosperm and embryo; (B) the decoated seeds with radicles exposed; (C) the excised embryos; (D) germination of excised embryos after $7 \mathrm{~d}$.

100 cabbage seeds were used for each extract. Seeds in each replicate petri dish were soaked in $5 \mathrm{~mL}$ of the extract solution for $3 \mathrm{~h}$, whereas control seeds were soaked in distilled water for the same period. The seeds were incubated in a growth chamber at $25^{\circ} \mathrm{C}$ with an 8 -h/16-h (light/dark) photoperiod. Seedling emergence was counted daily for $6 \mathrm{~d}$. A seedling was classified as emergent in accordance with the ISTA (2011) rules. Germination percentage was calculated based on the number of normal seedlings that emerged as a proportion of the total number of seeds sown.

Evaluation of methods to break seed dormancy. We applied the following treatments to evaluate their capability to break the dormancy of $C$. florida seeds. In treatment 1 , seeds were immersed in $500 \mathrm{mg} \cdot \mathrm{L}^{1} \mathrm{GA}_{3}$ for $48,60,72$, and $84 \mathrm{~h}$ at room temperature. A parallel control was conducted using seeds imbibed in water for $84 \mathrm{~h}$ without $\mathrm{GA}_{3}$. The water or $\mathrm{GA}_{3}$ solution was changed twice daily (Hartmann et al., 1989). After soaking, the seeds were stratified at $5{ }^{\circ} \mathrm{C}$ (cold stratification) for $90 \mathrm{~d}$. In treatment 2 , seeds were soaked as in treatment 1 , but were stratified during the $\mathrm{d}$ at $15^{\circ} \mathrm{C}$ and during the night at $5{ }^{\circ} \mathrm{C}$ (alternative stratification) for $90 \mathrm{~d}$. During stratification, water was added to keep the sand with water-holding capacity of $50 \%$ to $60 \%$. In treatment 3 , seeds were soaked in concentrated sulfuric acid (98\%) with seeds: acid of $1: 2(\mathrm{v} / \mathrm{v})$ for $0,5,10$, or $20 \mathrm{~min}$ (chemical scarification). During treatment, the solutions were stirred continuously with a glass rod. After chemical scarification, the seeds were washed in running water for $24 \mathrm{~h}$. Next, the seeds were soaked in $500 \mathrm{mg} \cdot \mathrm{L}^{-1}$ $\mathrm{GA}_{3}$ for $72 \mathrm{~h}$ and stratified at $5{ }^{\circ} \mathrm{C}$ for $60 \mathrm{~d}$.

After completion of the stratification treatment, the germinability of four replicates of
50 seeds each was tested in moistened sand at $25{ }^{\circ} \mathrm{C}$ with an 8-h/16-h (light/dark) photoperiod. The number of germinated seeds was counted every other day for $30 \mathrm{~d}$. During the germination test, water was added to keep the seeds moist. A seedling was classified as emergent in accordance with the ISTA (2011) rules. The germination percentage was calculated as described above.

Statistical analysis. A completely randomized design was used in all experiments. The effect of the treatments was assessed by the final germination percentage for each trial. The significance of differences between the means was assessed using the least significant difference (LSD) test with SPSS v19.0 (http:// support.spss.com/).

\section{Results} cracked seeds absorb water more rapidly than the intact seeds. The water uptake by cracked seeds increased to a saturation level of $16.9 \%$ in $24 \mathrm{~h}$, and then leveled off. In contrast, the water uptake by intact seeds only increased to $7.3 \%$ in $24 \mathrm{~h}$, and it would take at least $168 \mathrm{~h}$ for the intact seeds to achieve a nearly saturation level of water uptake (Fig. 2).

Germination after mechanical manipulation of seeds. The excised embryos showed no dormancy. After incubation for $7 \mathrm{~d}$, the embryonic axis elongated and the cotyledons of excised embryos started to expand and turned green (Fig. 1D). The germination percentage was $85.3 \%$ after $16 \mathrm{~d}$ of incubation. In contrast, the germination percentage of decoated and radicle-exposed seeds were only $13.3 \%$ and $28.8 \%$, respectively, after $16 \mathrm{~d}$ of incubation.

Inhibitor activity of extracts from $C$. florida seeds. Extracts from the excised
Water absorption by C. florida seeds. The embryos of $C$. florida showed no significant effect on cabbage seed germination $(P=$ 0.217) comparing to the control, whereas extracts from the endosperm significantly $(P<0.001)$ reduced the percentage germination of cabbage seeds from $99.3 \%$ (control) to $53.0 \%$. Soaking cabbage seeds in the same concentration of extracts from the endocarp had an even more significant $(P<0.001)$ negative effect on cabbage seed germination (reduced to $2.7 \%$ ). It indicates that both the endosperm and the endocarp contain endogenous inhibitors, which play an important role in the dormancy of $C$. florida seeds.

Effects of cold and chemical scarification on C. florida seed germination. Germination responses under different $\mathrm{GA}_{3}$ soaking periods combined with stratification treatments showed significant differences. Generally, with increasing duration of soaking in $\mathrm{GA}_{3}$ up to $72 \mathrm{~h}$, seed germination increased significantly $(P<0.05)$ in both treatment 1 and treatment 2. Compared with the control (soaking in $\mathrm{GA}_{3}$ for $0 \mathrm{~h}$ combined with $90 \mathrm{~d}$ of cold stratification), for which $22.3 \%$ germination was recorded, seed germination increased to $79.0 \%$ when seeds were soaked in $\mathrm{GA}_{3}$ for $72 \mathrm{~h}$ followed by $90 \mathrm{~d}$ of cold stratification (Table 1). For the same duration of soaking in $\mathrm{GA}_{3}$, germination in treatment 1 (cold stratification) was slightly higher than that in treatment 2 (alternative stratification), except for soaking in $\mathrm{GA}_{3}$ for 0 and $60 \mathrm{~h}$ (Table 1). Statistical analysis showed that the effect on seed germination of cold stratification was not significantly different from that of alternative stratification $(P>0.05)$. However, we observed that the germination speed was more erratic when seeds were treated with alternative stratification. Therefore, seeds were only cold stratified at $5{ }^{\circ} \mathrm{C}$ (cold stratification) in treatment 3 . It is also notable that soaking seeds in $\mathrm{GA}_{3}$ for $72 \mathrm{~h}$ had the best effect on seeds germination in both treatment 1 and treatment 2 (Table 1), thus only $72 \mathrm{~h}-\mathrm{GA}_{3}$ soaking was performed in treatment 3 .

To shorten the duration of cold stratification, seeds were scarified in sulfuric acid before $\mathrm{GA}_{3}$ soaking $(72 \mathrm{~h})$ in treatment 3 . With chemical scarification, most seeds germinated at cold stratification of $60 \mathrm{~d}$, and we achieved seed germination percentage of $81.8 \%$ at cold stratification of $60 \mathrm{~d}$ when seeds were first scarified in sulfuric acid for 10 min (Table 1). Thus, chemical scarification shorten the duration of cold stratification from 90 to $60 \mathrm{~d}$. However, if we increased the scarification duration to $20 \mathrm{~min}$, seed germination percentage would be greatly reduced (lowered to $5.5 \%$ ). This indicated that excessive chemical scarification would cause damage to the seeds.

\section{Discussion}

Causes of C. florida seed dormancy. Water uptake is a fundamental requirement for the completion of seed germination (Manz et al., 2005). In this study, water absorption by intact seeds increased slowly 


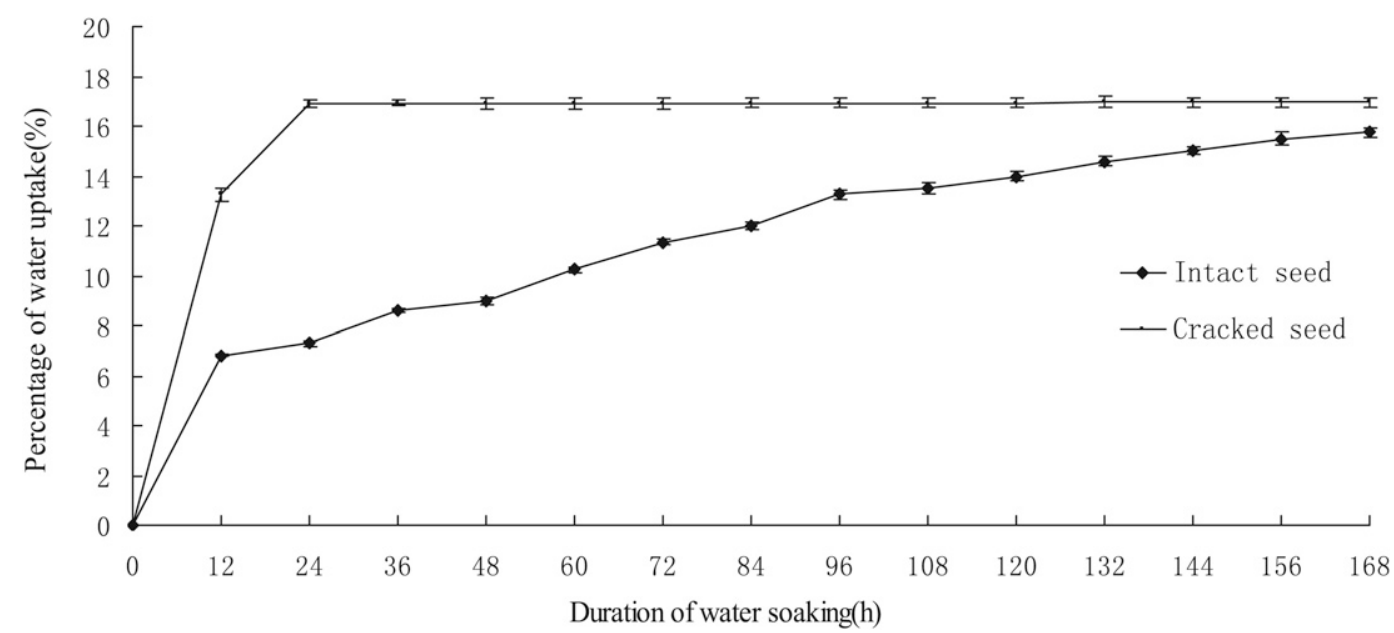

Fig. 2. Water absorption curves of the intact and cracked seeds of $C$. florida.

Table 1. Effects of different treatments on C. florida seed germination.

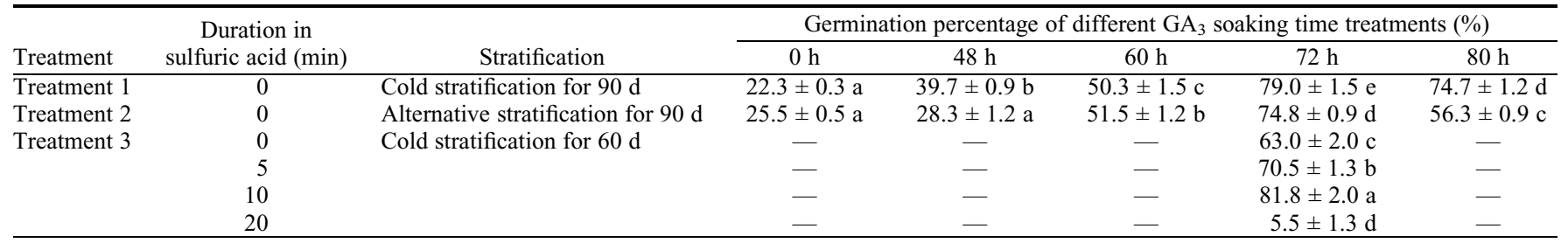

Values of germination percentage are displayed with the mean $\pm \operatorname{SE}(n=50)$. In treatment 1 and treatment 2 , germination percentages followed by the same letters in the same row indicated no significant difference at $P \leq 0.05$ by the LSD test, whereas those followed by different letters in the same row indicated significant difference at $P \leq 0.05$ by the LSD test. Both treatment 1 and treatment 2 indicated that soaking seeds in $\mathrm{GA}_{3}$ for $72 \mathrm{~h}$ had the best effect on seed germination, thus only $72 \mathrm{~h}-\mathrm{GA}_{3}$ soaking was performed in treatment 3 ("—" indicates germination is not carried out at the corresponding period of $\mathrm{GA}_{3}$ treatments). In treatment 3 , significance test was made for germination percentages of seeds soaking in sulfuric acid for different duration.

to $15.8 \%$ after imbibition for $168 \mathrm{~h}$ (Fig. 2). This finding indicated that the endocarp of $C$. florida could restrict water uptake and that might be one cause of seed dormancy. However, water uptake by seeds with a cracked endocarp was $16.9 \%$, only marginally higher than that of intact seeds, which was even lower than that of intact seeds from C. kousa var. chinensis (Fu et al., 2013). Thus the water content was likely to be inadequate for the metabolic processes required for germination. Therefore, in addition to the endocarp, the endosperm may also retard water absorption. The identity of factors that influence water uptake and the water absorption mechanism in C. florida requires further exploration.

Laufmann and Wiesner (1998) reported that the cotyledons of eastern dogwood $(C$. florida L. cv. Small) significantly inhibited germination of excised embryos. In this study, the germination percentage of excised embryos with cotyledons was $85.3 \%$, and extracts from excised embryos did not inhibit the germination of cabbage seeds. Thus, the cotyledons did not inhibit the germination of excised embryos of $C$. florida seeds. Fu et al. (2013) also found that there was no dormancy in the excised embryos with cotyledons of $C$. kousa var. chinensis. We proposed that the effect of cotyledon on seed dormancy might vary among different Cornus species. Germination of decoated and radicle-exposed seeds was significantly lower than that of excised embryos, which indicated that the endosperm was a barrier to seed germination. Extracts from the endosperm and endocarp significantly decreased cabbage seed germination, which suggested that an endogenous inhibitor might contribute to $C$. florida seed dormancy. Our findings indicate that seeds of C. florida show both physical and physiological dormancy as the restriction of water absorption and the inhibition of extracts, which belongs to the combinational dormancy category according to the seed dormancy classification of Baskin and Baskin (2004).

Methods of breaking C. florida seed dormancy. Many procedures, such as stratification with low or alternate temperatures (Ertekin, 2010; Li et al., 2013; Murat et al., 2010), plant hormones, and other chemical treatments ( $\mathrm{Li}$ et al., 2012; Mark, 1994) are effective in overcoming seed dormancy in a wide variety of species (Bewley and Black, 1982; Cohn, 1987, 1990; Laufmann and Wiesner, 1998). To break the physical dormancy, sulfuric acid is the effective scarifying agent (Bhatt et al., 2000). The data reported herein showed that soaking seeds with $500 \mathrm{mg} \cdot \mathrm{L}^{-1} \mathrm{GA}_{3}$ for $72 \mathrm{~h}$ combined with cold stratification was effective to break seed dormancy of $C$. florida (Table 1), while it required a long period of cold stratification $(90$ d). Soaking seed in sulfuric acid $(98 \%)$ for $10 \mathrm{~min}$ before $\mathrm{GA}_{3}$ treatment would reduce cold stratification requirement to
60 d. Immersion of C. florida seeds in sulfuric acid scarified the hard endocarp, which would accelerate water absorption and gas exchange, and ultimately results in rapid and uniform germination (Everitt, 1983; Hartmann et al., 1989). However, soaking the seeds in sulfuric acid for longer time would drastically decrease the germination percentage (Table 1), indicating excessive scarification would damage the seeds. Based on our study, rapid promotion of $C$. florida seed germination was achieved by immersing seeds in sulfuric acid for $10 \mathrm{~min}$ before soaking in $500 \mathrm{mg} \cdot \mathrm{L}^{-1} \mathrm{GA}_{3}$ for $72 \mathrm{~h}$ followed by cold stratification at $5{ }^{\circ} \mathrm{C}$ for $60 \mathrm{~d}$. As a conclusion, we have established an appropriate method to break $C$. florida seed dormancy that can be applied in practical seed reproduction practice.

\section{Literature Cited}

Baskin, J.M. and C.C. Baskin. 2004. A classification system for seed dormancy. Seed Sci. Res. 14:1-16.

Bewley, J.D. and M. Black. 1982. Viability, dormancy and environmental control. Physiology and biochemistry of seeds in relation to germination, Vol. 2. Springer-Verlag, New York, NY.

Bhatt, I.D., R.S. Rawal, and U. Dhar. 2000. Improvement in seed germination of Myrica esculenta Buch.- Ham. Ex D. Don: A high value tree species of Kumaun Himalaya, India. Seed Sci. Technol. 28:597-606. 
Borer, C.H., S.G. Sapp, and L.H. Hutchinson. 2013. Flowering dogwood (Cornus florida L.) as mediator of calcium cycling: New insights are revealed by analysis of foliar partitioning. Trees 27:841-849.

Coartney, J.S., W.R. Luckham, and P.L. Smeal. 1989. A guide to the commercial production of dogwoods, Vol. 430. Virginia Cooperative Extension Service.

Cohn, M.A. 1987. Mechanisms of physiological seed dormancy. Symposium on seed and seedbed ecology of rangeland plants, p. 21-23. Tucson, AZ.

Cohn, M.A. 1990. Factors influencing the efficacy of dormant-breaking chemicals, p. 261-267. In: R.B. Taylorson (ed.). Recent advances in the development and germination of seeds.. Plenaum Press, New York, NY.

Dirr, M.A. and C.W. Heuser. 1987. The reference manual of woody plant propagation: From seed to tissue culture. Varsity Press, Athens.

Ertekin, M. 2010. Improving germination of Judas tree (Cercis siliquastrum) seeds by hormone treatment. Seed Sci. Technol. 38:595-601.

Everitt, J.H. 1983. Seed germination characteristics of three woody plants species from south Texas. J. Range Mgt. 36:411-414.

Fu, X.X., H.N. Liu, X.D. Zhou, and X.L. Shang. 2013. Seed dormancy mechanism and dormancy breaking techniques for Cornus kousa var. chinensis. Seed Sci. Technol. 41:458-463.
Hartmann, H.T., D.E. Kester, and E.T. Davies. 1989. Plant propagation: principals and practices, 5 th ed. Prentice Hall, Englewood Cliffs, NJ.

Holzmueller, E.J., S. Jose, and M.A. Jenkins. 2007. Relationship between Cornus florida L. and calcium mineralization in two southern Appalachian forest types. For. Ecol. Mgt. 245:110-117.

Hou, J., H.L. Liu, Q.Y. Ma, W.W. Wei, T.M. Yin, and S.X. Li. 2014. Development of dormancy in seeds of Sapium sebiferum (L.) Roxb. during maturation. Prop. Ornam. Plants 14:13-19.

ISTA, International Seed Testing Association. 2011. International rules for seed testing. International Seed Testing Association, Zurich, Switzerland.

Laufmann, J.E. and L.E. Wiesner. 1998. Rapid germination of eastern dogwood (Cornus florida L. cv. Small) using embryo extraction, cut cotyledons and gibberellic acid. Seed Technol. 20:99-105.

Li, S.X., H.B. Gu, Y. Mao, T.M. Yin, and H.D. Gao. 2012. Effects of tallow tree seed coat on seed germination. J. For. Res. 23:229-233.

Li, S., T. Shi, F. Kong, Q. Ma, Y. Mao, and T. Yin. 2013. Methods for breaking the dormancy of eastern redbud (Cercis canadensis) seeds. Seed Sci. Technol. 41:27-35.

Manz, B., K. Müller, B. Kucera, F. Vollke, and M.G. Leubner. 2005. Water uptake and distribution in germinating tobacco seeds investi- gated in vivo by nuclear magnetic resonance imaging. Plant Physiol. 138:1538-1551.

Mark, P.B. 1994. A review of plant embryo culture. HortScience 29:1243-1246.

McLemore, B.F. 1990. Cornus florida L. flowering dogwood. Silvics of North Amer. 2:278.

Murat, Z., T. Zeynal, and U. Halil. 2010. The effects of different acid treatment and stratification duration on germination of Cercis siliquastrum L. seeds. Not. Bot. Hort. Agrobo. 38:159-163.

Paul, F.S. and J.G. David. 2008. Loss of Cornus florida L. leads to significant changes in the seedling and sapling strata in an eastern deciduous forest. J. Torrey Bot. Soc. 135:506515.

Rushforth, K. 1999. Trees of Britain and Europe. HarperCollins Publisher, London.

Stiles, E.W. 1980. Patterns of fruit presentation and seed dispersal in bird-disseminated woody plants in the eastern deciduous forest. Amer. Nat. 116:670-688.

Thomas, W.A. 1969. Accumulation and cycling of calcium by dogwood trees. Ecol. Monogr. 39:101-120.

United States Department of Agriculture, National Agricultural Statistics Service (USDA-NASS). 2010. Department of Agriculture, Washington DC. 